\title{
INTERFACEAMENTOS CONTEMPORÂNEOS: TECNOLOGIAS DIGITAIS E TRIBOS URBANAS NO CONTEXTO ESCOLAR
}

Valdirene Cássia da Silva*

Edvaldo Souza Couto**

RESUMO: O artigo apresenta resultados de uma pesquisa sobre juventudes, tribos urbanas e as interfaces com as tecnologias de informação e comunicação, no contexto escolar de Palmas-TO. Foram estudados jovens que se assumem como integrantes de tribos que circulam pela cidade e estudam no Centro de Ensino Médio - CEM. A investigação esteve atrelada a uma perspectiva formativa escolar oficial e a seleção e oferta de conteúdos paralelos, mediados pelas tecnologias digitais, que possibilitam interações coletivas e reorganizam as experiências de vida dos sujeitos. O método, análise de conteúdo, foi adotado para a leitura e a interpretação das informações obtidas durante o processo da pesquisa. Os resultados indicam que tipologias distintas de jovens circulam no cenário escolar, convivem com as ofertas das políticas educacionais e formativas e negociam mais sentidos e significados da cultura digital em suas vidas.

Palavras-chave: Juventudes. Cibercultura. Educação.

\section{CONTEMPORARY INTERFACES:}

DIGITAL TECHNOLOGIES AND URBAN TRIBES IN THE CONTEXT OF SCHOOLING

ABSTRACT: The article presents the results of a piece or research about juveniles, "urban tribes" and their interactions with information technology and communication in the school context of Palmas-TO Those studied were youths, seeing themselves as members of tribes circulating the city, and studying at the Centre for Middle Teen Education. The investigation was carried out according to an official school perspective and the selection and offering of parallel contents, provided via digital technologies, permitted collective interactions and helped reorganize of the life experiences of the subjects. During the research process, the method - analysis of contents - was adopted for the study of the literature and the interpretation of the information obtained. The results show that distinct youth types circulate the school scene, living alongside the educational policies. Also, these types are able to negotiate a broad range of feelings and meanings from the digital culture pervading their lives. Keywords: Youth. Cyber-culture. Education.

\footnotetext{
* Doutoranda em Educação pela Universidade Federal da Bahia (UFBA) e Professora na Universidade Luterana do Brasil (ULBRA). E-mail: valdirene.silva0@gmail.com

** Doutor em Educação pela Universidade Estadual de Campinas (UNICAMP); Professor na graduação e pós-graduação em Educação na Universidade Federal da Bahia (UFBA) e pesquisador do Conselho Nacional de Desenvolvimento Científico e Tecnológico (CNPq). E-mail: edvaldo@ufba.br
} 


\section{Relevância e atualidade do estudo proposto}

Os anos de trabalho com a organização curricular e a gestão operacional, o cotidiano das salas de aula no ensino superior, na Fundação Universidade do Tocantins (Unitins) e no Centro Universitário Luterano de Palmas (Ceulp/Ulbra) possibilitaram escutas, falas, diálogos e até mesmo conflitos-confrontos com parte de um coletivo de professores habilitados para atuar nas licenciaturas. Isso agregou-nos uma certeza: o ato de aprender é pensado como movimento que se realiza em um fluxo sujeito-objeto, no qual a incorporação do último garante a transformação do primeiro.

Embora termos e expressões da moda, como "professor reflexivo", "professor dialógico" ou "aluno construtor de seu conhecimento" estejam presentes nos projetos pedagógicos dos cursos de Pedagogia, Normal Superior, Letras, Matemática, Geografia e História do Programa de Licenciaturas Parceladas, proposto pelo convênio Secretaria Estadual de Educação e Cultura - Fundação Universidade do Tocantins (Seduc Unitins) e Secretaria Municipal de Educação e Cultura - Fundação Universidade do Tocantins (Semec - Unitins), um currículo oculto se faz presente na realização dos cursos e encontra solo propício junto aos 4 mil professores leigos em exercício nas unidades escolares do estado do Tocantins. A base desse currículo subjacente é a relação da escola com as tecnologias contemporâneas, temática explorada por vários pesquisadores do campo da cibercultura, entre eles: Kenski (2004); Pretto (1999); Bonilla (2005); Couto (2010).

Percebemos que a sociedade contemporânea está marcada pela produção de inovações (científicas, cognitivas, tecnológicas) e pelo processo incessante de circulação da informação. Os alunos passaram a viver sob a cultura da inovação, absorvendo com velocidade tudo o que ocorre. Porém, em inúmeros casos, a escola e os professores ainda parecem viver sob o signo de outra velocidade, extremamente morosa e conservadora.

Nesse contexto, o artigo apresenta resultados de uma pesquisa intitulada "Corpos híbridos em mentes diáfanas: as tribos urbanas no universo escolar de Palmas e suas interações com as tecnologias da informação e da comunicação", realizada nos anos de 2006 e 2007, com as tribos insertas no Centro de Ensino Médio - CEM de Palmas. O objetivo geral desse estudo foi analisar as interfaces - entendidas como processo de 
interação - das tecnologias digitais e tribos urbanas, na contemporaneidade escolar. Os objetivos específicos foram descortinar determinadas concepções errôneas sobre as juventudes nos cenários da escola e sinalizar outras possibilidades de se pensar-agir dos docentes em suas intervenções pedagógicas, observando o respeito e o compartilhar das novas configurações culturais.

\section{Objeto de estudo}

O objeto deste estudo são as tribos urbanas e suas interações com as tecnologias da informação e comunicação (TIC), no contexto escolar, mais especificamente no CEM de Palmas-TO. O conceito de "tribo urbana" aqui utilizado é do sociólogo Maffesoli (2000). De acordo com esse autor, essa expressão representa a junção dos novos grupamentos sociais (tribos) com os espaços de associação da sociedade "pósmoderna" (urbes). Trata-se de uma espécie de "neotribalismo", microgrupos sociais cujas identidade e sociabilidade são marcadas pelo individualismo, pela unissexualização da aparência física, do corpo e da moda: pequenos grupos delimitados nas sociedades complexas que elaboram e dispõem de suas próprias regras, nas quais, além das influências tradicionais das famílias, encontramos traços do universo formativo fundamentado nas tecnologias digitais.

Tapscott (1998) assegura que os jovens que estão em contato permanente com as TIC são marcados por uma mutabilidade constante. Tecnófilos, esses jovens se sentem atraídos e assumem de fato essas tecnologias para a satisfação de suas necessidades de lazer, comunicação e aprendizagem. Dominando tais tecnologias, essa geração, por meio da usabilidade e da navegabilidade, adquire uma competência de manipulação de todo o aparato tecnológico a que tem acesso. Disso resulta a vulnerabilidade ao consumo e ao descarte de objetos, relacionamentos e sentimentos, o que implica novas perspectivas éticas e morais, que impregnam os jovens urbanos, visuais, auditivos e cinestésicos: no intercâmbio com as TIC e suas aplicações, agem como se estivessem manuseando os mesmos programas e softwares na vida cotidiana. Praticamente, não existe diferenciação entre os domínios do digital e da realidade concreta. 
O objetivo geral da pesquisa foi compreender e analisar as tribos urbanas existentes no universo escolar, na contemporaneidade, como conjuntos sociais diversificados, e suas interações com as TIC. A pesquisa caminhou pelas seguintes questões norteadoras: a) as tribos urbanas, cada vez mais inseridas nos espaços escolares, se apropriam de elementos estéticos, linguagem, estilo de vida e formas de apreender o mundo a partir das TIC; b) no universo escolar, verifica-se um distanciamento do pensar-refletir as diversas formas de apreensão do mundo pelas tribos urbanas a partir das TIC; c) novas experiências formativas estão entrando no universo escolar, a partir das tribos urbanas, regidas por negociações midiáticas e alavancados pelas TIC.

Estilos de vida, possibilidades de outros comportamentos, representações estéticas, usos e manejos das tecnologias digitais, entre conflitos e confrontos curriculares, são possibilidades abertas para investigar as juventudes, a partir das tribos que se encontram no espaço do CEM. E, além disso, contribuir para o aprofundamento dos estudos que visam a compreender essas novas possibilidades de os jovens estarem no mundo, bem como as lógicas de reconhecimento dessas possibilidades, frente à tecnologia e à educação como um todo.

\section{Aproximações teóricas}

No contato com grupos de jovens, de aproximadamente 16 aos 24 anos, no CEM de Palmas, e dos espaços universitários da Unitins e do Ceulp-Ulbra, no que tange ao uso e ao consumo de bens simbólicos mediados pelas TIC (em especial, aqueles difundidos pela mídia radiofônica, publicitária e televisiva), teve-se a impressão de que a oferta de uma imagem-identidade de juventudes é determinantemente produzida pelo currículo escolar do Ensino Médio; e que o uso-consumo dos bens simbólicos mediados pelas TIC apresenta outros projetos formativos.

Histórica e socialmente, a juventude tem sido considerada como fase de vida marcada por certa instabilidade, associada a determinados "problemas sociais". O modo de apreensão desses problemas varia no tempo histórico e de acordo com a ciência que sobre eles se debruçam. Os estudos de viés psicológico tendem a privilegiar os aspectos negativos das juventudes, sua instabilidade, sua irreverência, sua insegurança e sua 
revolta. Os estudos sociológicos ora investem nos atributos positivos dos segmentos juvenis, responsáveis pela mudança social, ora acentuam a dimensão negativa dos "problemas sociais" e do desvio.

Podemos dividir os autores que se dedicaram ao tema da juventude em dois grandes blocos: o primeiro compreende os trabalhos que consideram a juventude como um conjunto social derivado de determinada fase de vida, com ênfase nos aspectos geracionais; para outros, a temática estaria subsumida no interior de outras dimensões da vida social, definidos a partir de universos mais amplos e diversificados, sobretudo aqueles derivados das diferentes situações de classe.

Para Machado (1993) a juventude é uma categoria socialmente construída, no contexto de particulares circunstâncias econômicas, sociais e políticas, e sujeita a modificar-se ao longo do tempo. As juventudes devem ser como um conjunto social diversificado, perfilando-se diferentes tipos, em função da realidade econômica, dos interesses e das oportunidades ocupacionais e educacionais.

De acordo com Morin (1984), a juventude existiria como um grupo de idade identificado aos modelos culturais das sociedades de massas. Chamboredon (1985) diz que a juventude enquanto categoria estaria dissolvida na inerente diversidade recoberta pelas múltiplas classes sociais. Dubet (1996) observa que, para se estabelecer um tratamento analítico sobre a noção de juventude, é preciso, preliminarmente, reconhecer que a moderna condição do jovem encerra uma tensão intrínseca. Para esse autor, a experiência desse momento de vida é construída em torno da formação moderna de um mundo juvenil relativamente autônomo e, ao mesmo tempo, como momento de distribuição dos indivíduos na estrutura social.

Para Atias-Donfut (1996), a realidade efervescente e essencialmente mutante dos jovens não poderia ser reduzida a uma dimensão unidirecional. Ela não será enfrentada a não ser que se conjuguem várias perspectivas para revelar suas diversas facetas e levar em conta sua complexidade.

No CEM, encontramos os grupos de jovens se autodenominando de tribos. Tribos referem-se a grupos de pessoas que se identificam por motivos diversos e acabam assumindo algumas características que os tornam facilmente identificáveis, porque caracterizados com roupas, acessórios, gosto musical, entre outros. Conforme Hall (1997, p. 49), "a lealda- 
de e a identificação que, numa era pré-moderna ou em sociedades mais tradicionais, eram dadas à tribo, à religião e à região, foram transferidas, gradualmente nas sociedades ocidentais à cultura nacional". $\mathrm{Na}$ atualidade, no entanto, a lealdade tribal pode estar sendo canalizada para as tribos urbanas, metáfora embrionária de novas sociabilidades, que criam essa identificação e lealdade pelos gostos estéticos, pelas atitudes, pela forma de se enquadrar nesse cotidiano estetizado.

No cenário palmense, a presença de diversas tribos no espaço escolar faz com que o tema "juventudes" adquira visibilidade e, consequentemente, suscite questões, principalmente no que se refere ao comportamento juvenil. A partir dos comportamentos socioculturais que estão em disputa e sendo ofertados, os jovens tendem a se agrupar em busca de autonomia. Assim, eles vão vivenciando novos espaços, provisórios, nômades e transitórios.

Para Maffesoli (2003), presenciamos um movimento típico da pós-modernidade, um novo tipo de tribalismo, por ele nomeado de neotribalismo, que foge das concepções clássicas, cuja marca fundante era a estabilidade. Agora, há uma busca pelo pertencimento, um dos traços característicos do neotribalismo - fenômeno ligado aos modos de vida e às subjetividades dos jovens urbanos na cibercultura - responsável por um mundo dominado pela moda, pelo consumo, pelo espetáculo e pela comunicação, em ambientes cada vez mais mediados pelas TIC.

Tipologias distintas de jovens vão se manejando no cenário escolar, convivendo com as ofertas das políticas educacionais e formativas que se presumem hegemônicas e, enquanto receptores, vão negociando mais sentidos e significados de mundo e vida.

\section{Procedimentos metodológicos}

A pesquisa de campo foi realizada no Centro de Ensino Médio de Palmas - CEM, com jovens de 16 a 24 anos. Foram entrevistados 35 alunos, matriculados no terceiro ano do Ensino Médio, divididos em três turmas (duas no turno matutino e uma, no noturno). Nesse universo, mediante observação, informações e entrevistas, nos propusemos compreender a realidade empírica e cotidiana dos grupamentos juvenis que se assumem como membros de tribos. Para a identificação da "tribo", con- 
sideramos características sociais, idade, gênero, situação econômica, étnica e uso das TIC.

A abordagem do estudo foi a qualitativa, pela necessidade de obtenção de dados descritivos dos grupamentos juvenis, a partir do seu ambiente e do processo de construção das relações com as TIC. O contato direto com o grupo estudado proporcionou um entendimento além do produto, mas com a preocupação de analisar como se processam as interações cotidianas dessas tribos com as TIC, buscando retratar as "perspectivas" dos seus membros, considerando seus diferentes pontos de vista.

Nesse percurso, dar voz aos sujeitos nos possibilitou a compreensão sobre as possibilidades de essas tribos estarem imersas em um mundo mediado pelos dispositivos tecnológicos comunicacionais, que lhes vêm possibilitando apropriações múltiplas. Optamos, pois, pela entrevista semiestruturada, permitindo ao entrevistado falar livremente sobre assuntos indicados ou que foram surgindo. A investigação foi enriquecida com o levantamento bibliográfico de teóricos que discutem a relação tribos urbanas e TIC. A perspectiva teórica dos autores contemplados foi o suporte para a observação, a compreensão e a análise do objeto estudado, em seus envolvimentos culturais, sociais (linguagem, estética, estilo de vida, vocabulário, simbolismos, etc.) e tecnológicos.

O pesquisador é aquele que vai ao encontro do outro. Colocando-se no lugar desse outro, percebe o que por ele (o outro) é percebido. Ao fazer isso, retorna ao seu lugar de origem. Desse retorno, surge, além da compreensão do outro, uma resposta ao objeto estudado, construída a partir do visto, dito e não-dito. Por isso, no processo investigativo, instauramos uma estratégia dialógico-textual que não desrespeitasse as normas de produção acadêmica e possibilitasse aos leitores-sujeitos socioeducativos compreender a proposta de estudo e seus resultados. Dessa maneira, assumimos uma postura didático-relacional, ampliamos e esclarecemos as inquietações das questões norteadoras da investigação, tendo em perspectiva a "Geração Net", que se configura como um conjunto de crianças, adolescentes e jovens que estão em contato permanente com as TIC, considerando-se proprietários delas (TAPSCOTT, 1998). 


\section{Relato da pesquisa}

Em nossos primeiros caminhos teóricos, aliamos contribuições de autores da educação, da antropologia, da sociologia, da filosofia, da comunicação e da administração que discutem aspectos da cibercultura. Nesse deslocamento teórico-metodológico, logramos construir, com menos tensões, a tela da pesquisa, a partir da realidade empírica, com rigor e comprometimento.

Assumimos que as juventudes não são uma mente-caixa vazia ou tábula rasa. Os corpos e as mentes juvenis, com suas expressões e manifestações no espaço educacional, se dão mediante o cruzamento da cultura escolar oficial e o popular urbano contemporâneo, seja este presente nos nichos familiar-comunitários, no coletivo dos bairros e em todas as associações esporádicas ou não que os jovens estabelecem na cidade.

Admitimos que o cultural escolar se presume um gênero de conteúdos puros e hegemônicos. Essa presunção implica um equívoco: o popular-urbano seria um gênero impuro, mas ele é, na verdade, a resistência ao hegemônico oficial, manifestação crítica de contraposição à ordem urbana globalizada, à crença nas instituições políticas e o desencanto utópico (CANCLINI, 1997).

Em virtude desses posicionamentos, optamos por considerar que a cultura formativa escolar maneja-se na seleção e na oferta de conteúdos determinados pelos grupos hegemônicos da sociedade e se deixa "contaminar" por outros formatos paralelos, mediados pelas TIC. O resultado desse manejo e dessa "contaminação" são possibilidades interativas subordinadas à cultura urbana e às tecnologias digitais.

Definida essa perspectiva, procuramos resgatar determinados conceitos, conceptualizações e angulações sobre tecnologia(s) e convergência midiática para agregar maior entendimento aos processos de fruição da juventude na sociedade contemporânea; a partir da sinalização teórica de vários pesquisadores, procuramos discutir juventude-adolescência e a configuração das tribos urbanas, em parte ampliando e esclarecendo as inquietações presentes nas questões norteadoras. Além disso, definimos e caracterizamos o universo da pesquisa - os alunos do Centro de Ensino Médio de Palmas. Analisamos os resultados obtidos e apresentamos algumas considerações necessárias ao entendimento mais aprofundado das tribos urbanas e suas interações com as TIC, no contexto escolar. 
Entre as descobertas realizadas nesta investigação, podemos destacar: a juventude possui corpos híbridos em mentes diáfanas, em decorrência das contínuas tentativas de consumo de produtos culturais postos pelo capitalismo contemporâneo. Por isso, pode ser assumida como fluida, líquida (BAUMAN, 2001), em suma, diáfana. Os desenhos curriculares continuam a oferecer conteúdos e um jeito de ser aluno em descompasso com a contemporaneidade e, ao mesmo tempo, assumindo apenas o lado deslumbrado das tecnologias como fontes miraculosas do saber para a inserção no mercado profissional. Mas os conteúdos extracurriculares, inclusive os midiatizados, oferecem possibilidades híbridas e diáfanas de agir e estar no mundo.

Para os jovens pesquisados, conhecimento implica o uso das TIC, o que reforça a relação de dependência entre eles. As tribos urbanas dos espaços escolares são um exemplo dessa relação, uma vez que se apropriam de elementos estéticos, linguagem, estilo de vida e formas de apreender o mundo a partir das TIC. A cultura juvenil trafega em meandros digitais, que possibilitam a formação de valores e de saberes expressos na linguagem, nas sociabilidades e na estética. O uso das tecnologias não é apenas um espaço de sociabilidades, mas, também, uma possibilidade de potencializar a economia pessoal.

Os jovens das classes médias altas imergem nas tecnologias para fazer parte do mundo tecnologizado; nossos entrevistados objetivam o mesmo, mas enxergam, além disso, a possibilidade de ganho financeiro por meio do uso das tecnologias. Isso nos levou a perceber que não existe uma relação de causa e efeito entre o nível socioeconômico dos jovens e o interesse pelas tecnologias: a influência de consumo midiático não se concentra em determinadas classes ou grupamentos. Entretanto, a funcionalidade do uso das TIC é diferente entre os dois grupos: o primeiro busca, predominantemente, a imersão no mundo tecnológico para expandir suas relações sociais; o segundo percebe nela, em primeiro plano, uma chance de transformar suas condições materiais de existência.

Se relacionarmos a lógica de ser jovem ao crescimento da cidade de Palmas, percebemos que ambos carregam em seus "corpos" traços da contemporaneidade: símbolos, emblemas, insígnias de um fazer midiático. Tanto a cidade quanto seus jovens têm uma formação a partir da grande oferta de bens simbólicos e culturais que se manifestam pelas TIC. Podemos afirmar, então, que Palmas é uma grande tribo mediada por 
essas tecnologias. Entre os aparatos tecnológicos consumidos pela juventude palmense, o aparelho celular se destaca. Os jovens revelam uma relação de dependência do celular. Além de meio de comunicação, esse artefato é fator imprescindível de atualização para o consumo e para as relações sociais. Ao aparelho é dada, ainda, uma conotação de instrumento de localização e vigilância social, ampliando sua funcionalidade, na medida em que, ao fazer o contato com as pessoas, localizaas no espaço geográfico.

A portabilidade e a interatividade desse aparelho são elementos importantes para esses jovens: imprimem neles a sensação de estar sempre conectados com as pessoas e com o mundo. O celular é como se fosse uma parte do corpo de seu usuário: associado aos braços, pernas, coração e mente, ajuda a configurar seu aspecto físico. O uso do celular faz com que os jovens vivenciem a sensação de estar constantemente on-line, o que permite os diversos deslocamentos virtuais pelos "lugares-no-tempo" dessas juventudes plugadas.

As tecnologias induzem os jovens a uma convivência em tribos: só entre eles é possível assegurar o contato necessário à comunicação do que percebem no mundo com a mediação das TIC. Mesmo possuindo culturas e repertórios diversificados, os jovens se agrupam em tribos porque fazem parte de uma mesma geração: a geração das tecnologias contemporâneas. Os gestores da escola apresentam dificuldade e resistência em compreender e aceitar que as tecnologias contemporâneas e suas potencialidades são fatos e que a juventude não se percebe no mundo sem a mediação delas.

As TIC são artefatos, dispositivos, mecanismos que ora armazenam, ora difundem dados e informações, portam estratégias políticas, econômicas e ideológicas de quem as produz e, ao serem transportadas e consumidas pela juventude, passam a ter outras possibilidades de usos e manejos, de produção de sentidos e significados. A cultura escolar teme os novos conteúdos que as TIC trazem para os espaços e tempos tradicionais da educação. Isso desloca a ideia do professor como depositário do saber e traz outros modelos de cooperação, colaboração e trocas simbólicas e materiais.

Acreditamos que espaço, tempo, sujeitos-docentes e sujeitos-alunos necessitam de uma pedagogia audiovisual que congregue as TIC em sua constituição teórica e metodológica. É preciso promover o desloca- 
mento da aprendizagem, a readequação de olhares e práticas pedagógicas voltados para as juventudes. O desafio para a pedagogia e a educação como um todo é aprender a valorizar, a entrar nesses espaços de participação e colaboração que as juventudes vêm estabelecendo.

Refletir e investigar as tribos urbanas e suas (inter)ações com as TIC foi buscar mais sinalizações para que as práticas formativas contribuam para novas práticas sociais, isto é, na dinamização de outros processos sociais importantes para a conquista de uma vida pública da juventude e com isso, buscando-se a construção de uma sociedade mais inclusiva.

\section{Algumas conclusões}

O estudo revelou que o perfil dos grupamentos juvenis, na contemporaneidade, é marcado pela mutabilidade constante: uma geração de jovens tecnófilos, atraídos pelas tecnologias e pelo desejo de conhecê-las e empregá-las. Essa condição os torna vulneráveis a todos os tipos de consumo e à descartabilidade de objetos, relacionamentos e sentimentos. Os jovens urbanos são marcados por traços visuais, auditivos e cinestésicos. No intercâmbio com as TIC e suas aplicações, agem como se estivessem manuseando os mesmos programas e softwares na vida cotidiana. Praticamente não existe, para eles, diferenciação entre os domínios do digital e da realidade concreta.

A pesquisa demonstrou, ainda, que as tecnologias digitais estão, cada vez mais, oferecendo um padrão comportamental aos jovens, pela intromissão de produtos culturais e de consumo e pelas ofertas de comercialização de sentidos. A cultura juvenil trafega em meandros digitais que possibilitam a formação de valores e de saberes, expressos na linguagem, nas sociabilidades e na estética. Há uma procura de propostas de outras sociabilidades e de sentido de existência dos grupamentos juvenis frente às tecnologias, mas não mais como meros processos de homogeneização.

Concluímos ainda que lidar com os avanços culturais da juventude provocados pelas tecnologias no Centro de Ensino Médio de Palmas ainda é um desafio. As potencialidades educativas das TIC fazem parte de um processo em construção. É importante que os atores socioeducativos conheçam e compreendam não apenas o significado que as tecnologias têm na vida dos jovens, mas também um novo pensar pedagógico que elas 
proporcionam. E assim entender, finalmente, os porquês do distanciamento desse universo para com as TIC.

Ficaram evidenciados também que processos pedagógicos deveriam, em função da emergência tecnológica, se modificar. São outras formas de aprender que estão sendo estabelecidas; modelizações mais atraentes que as tecnologias estão convidando a realizar. Percebemos, durante as intervenções, que esses jovens não querem ser ensinados, mas conduzidos à construção, às descobertas. É a questão da autoria que está muito latente em meio a esses grupos juvenis. Esses trazem para a escola mais saberes. O desafio para a pedagogia e a educação como um todo é aprender a valorizar, a entrar nesses espaços de participação e colaboração que a juventude vem estabelecendo. Essas são possibilidades de instauração de novas realidades educacionais. 


\section{Referências}

ATTIAS-DONFUT, Claudine. Jeunesse et conjugaison des temps. Sociologie et sociétés, v. XXVIII, n. 1, 1996.

BAUMANN, Zygmunt. Modernidade líquida. Trad. Plínio Dentzien. Rio de Janeiro: Jorge Zahar, 2001.

BONILLA, Maria Helena. Escola Aprendente. São Paulo: Quartet, 2005.

CANCLINI, Néstor Garcia. Culturas híbridas: estratégias para entrar e sair da modernidade. São Paulo: Edusp, 1997.

CHAMBOREDON, J C. Adolescence et post-adolescence: la juvénisation. In: ALEON; MORVAN; LEBOVICI. Adolescence terminée, Adolescence interminable. Paris: PUF, 1985.

COSTA, Antônio Carlos Gomes da. Protagonismo Juvenil: adolescência, educação e participação democrática. Salvador: Fundação Odebrecht, 2000.

COSTA, Márcia Regina da. Tribos urbanas nas identidades das metrópoles. ECCOS Revista científica, São Paulo: Uninove, n. 1, v. 3, p. 41-55, 2001.

COUTO, Edvaldo Souza. Corpos modificados: o saudável e o doente na cibercultura. In: LOURO, Guacira; FELIPE, Jane; GOELLER, Silvana (Orgs.) Corpo, gênero e sexualidade: um debate contemporâneo na educação. 6 ed. São Paulo: Vozes, 2010.

DUBET, F. Des jeunesses et des sociologies. Le cas français. Sociologie et sociétés, v. XXVIII, n. 1, 1996.

GORCZEVSKI, D. O hip-hop e a (in)visibilidade no cenário midiático. Dissertação (Mestrado em Ciências da Comunicação) - São Leopoldo: Unisinos, 2002.

HALL, Stuart. A identidade cultural na pós-modernidade. Trad. Tomaz Tadeu da Silva, Guacira Lopes Louro. Rio de Janeiro: DP\&A, 1997.

KENSKI, Vani Moreira. Tecnologia e ensino presencial e a distância. 2 ed. Campinas, SP: Papirus, 2003.

MACHADO, José Pais. Culturas Juvenis. Lisboa: Imprensa Nacional - Casa da Moeda, 1993.

MAFFESOLI, M. O tempo das tribos: o declínio do individualismo nas sociedades de massa. 3 ed. Rio de Janeiro: Forense Universitária, 2000.

MORIN, E. Cultura de massas no século XX. Neurose Rio de Janeiro: Forense Universitária, 1984. (v. I)

PRETTTO, N. L. Educação e inovação tecnológica: um olhar sobre as políticas públicas brasileiras. Revista Brasileira de Educação, São Paulo, n. 11, p. 75-85, 1999.

SILVA, Tomaz Tadeu. Documentos de identidade: uma introdução às teorias do currículo. 2 ed. Belo Horizonte: Autêntica, 2004.

TAPSCOTT, Don. Geração Digital. São Paulo: Makron Books do Brasil, 1999. 
Recebido: 13/12/2010

Aprovado: 19/10/2011

Contato:

CEULP-ULBRA

108 Norte

Avenida JK, 10

Arne 13

CEP 77006-094

Palmas, TO

Brasil

Educação em Revista | Belo Horizonte | v.28 | n.02 | p.333-346 | jun. 2012 